\title{
$\mathrm{LCD}$ 콘솔용 냉각장치의 제어기 설계에 관한 연구 \\ 최갑용 ${ }^{1}$, 오태일 ${ }^{1 *}$ \\ ${ }^{1}$ 아주자동차대학 자동차계열
}

\section{A Study on the Controller Design of Cooling System for LCD Panel Console}

\author{
Kab-Yong Choi ${ }^{1}$ and Tae-Il Oh ${ }^{1 *}$ \\ ${ }^{1}$ Division of Automobile, Ajou Motor College
}

\begin{abstract}
요 약 본 연구는 옥외 광고를 위한 LCD 패널용 콘솔(이하 콘솔'이라 한다.)"의 내부온도 제어를 위한 냉각장치의 제어기 설계에 관하여 다루고 있다. 콘솔은 본 연구진에 의하여 개발된 것으로 냉각장치는 열전소자를 이용하여 사용 조건에 적합하도록 설계하였다. 아울러 본 연구는 콘솔이 우수한 성능을 발휘할 수 있도록 제어전략과 그 방안을 제 안하고자 한다. 본 연구의 구성은 먼저 시스템의 구조와 설계조건에 대하여 정의하였다. 이어서 동적 특성을 결정하 는 파라미터를 측정한 후 분석을 위하여 시스템을 수식 모델링하였다. 끝으로 제어전략을 수립한 후 수식모형을 이용 하여 제어기의 성능 검사를 위한 시뮬레이션을 실시하고 기존의 제어기 성능과 비교분석하였다. 본 연구의 목적은 비 교분석을 통하여 보다 개선된 제어방식을 제시하는 것이다.
\end{abstract}

\begin{abstract}
This study dealt with the controller design of the cooling system for controlling the inside temperature of the LCD panel console(the rest console') using as an outdoor billboard. The cooling performance of the LCD console that had been developed by the preceding research, was insufficient in the performance of the controller. In order to improve the performance of the system, in this study defined the structure and the design condition of the system first, after measured the parameters having influence on the dynamic characteristics, and developed the mathematical model for the analysis of the system. Finally planned a controlling scheme of the system and simulated the controller for the performance checking, compared the performance of this system controller with the preceding one. The purpose of this study is the presentation of the more improving method for the system control
\end{abstract}

Key Words : Cooling System, Controller, LCD panel, Parameters, Dynamic Characteristics, Mathematical Model

\section{1. 연구의 개요와 목적[1]}

그림 1 은 본 연구의 대상이 되는 냉각장치가 탑재된 콘솔이다. 콘솔은 본 연구진이 개발한 것으로 개발목적은 소규모 경영단위나 기업의 경쟁력을 제고 할 수 있도록 하는데 있다. 46 인치 규모의 LCD 패널을 탑재하고 있는 콘솔은 주로 옥외에 설치되기 때문에 보호와 안전을 위 하여 패널의 화면을 제외한 모든 면을 강판으로 둘러싸 서 밀폐되도록 제작하였다. 이 때문에 LCD 패널이 작동 할 때 발생하는 열이 외부로 발산하지 못하고 콘솔의 내
부에 쌓이는 문제점을 가지고 있다. 실험 결과 내부온도 는 거의 $90^{\circ} \mathrm{C}$ 정도로 과열되었다. 콘솔은 과열상태를 방 지하기 위하여 냉각장치를 채용하여 권장온도 $30^{\circ} \mathrm{C}$ 정도 로 유지하도록 설계되어야 한다. 콘솔의 냉각장치는 열전 소자(TEM, Thermo Electronic Module)를 이용하여 개발 하였다. 그 이유는 기계식 냉각시스템은 중후장대(重厚長 大)하고 소음과 잦은 보수 등의 문제점을 가지고 있기 때 문이다. 본 냉각장치는 TEM, 쿨링팬(Cooling Fan),과 히 트싱크('Heat sinks) 등으로 이루어져 있기 때문에 경박단 소(輕薄短小)하면서도 유지보수에 유리한 장점을 가지고

*교신저자 : 오태일(tioh@motor.ac.kr)

접수일 10 년 08 월 31 일 수정일 10 년 10 월 03 일 게재확정일 10 년 10 월 15 일 
있다.
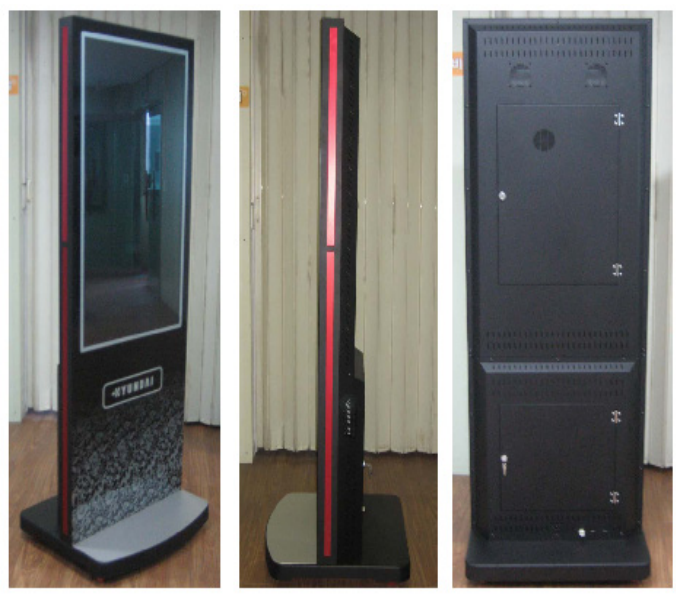

[그림 1] LCD 콘솔의 외관

선행연구에서 제안된 냉각장치의 제어기는 정밀성에 문제가 대두되었다.

따라서 본 연구의 목적은 선행연구에서 제기된 문제를 해결하기 위한 냉각장치의 성능을 효과적으로 개선할 수 있는 제어기 설계를 제안하는데 있다. 이를 위하여 본 연 구에서는 시스템 모델링과 분석을 통하여 기존의 방법보 다 우수한 제어기를 제안하는 과정을 보이고자 한다.

\section{2. 시스템 구조와 제어전략}

\section{1 시스템의 구조와 설계조건[2]}

콘솔의 구성은 그림 2 에서 보는 바와 같이 46 인치 LCD 패널, 냉각실(Cooling Chamber), 제어부(Sensor \& Controller), 냉각장치(Cooling System) 등으로 구성되어 있다. $\mathrm{LCD}$ 패널이 작동되면 발광보드에서 열이 발생하 여 냉각실에 축적된다. 냉각실의 온도 정보는 센서를 통 하여 제어기로 보내면 기준입력과 비교하여 제어알고리 즘을 작동시켜서 필요한 냉기의 수준을 결정하여 최종 제어요소인 냉각장치를 가동시킨다. 냉기는 냉각장치 아 래쪽에 있는 송풍기를 이용하여 냉각실로 보내진다. 이와 같은 과정을 반복하여 $\mathrm{LCD}$ 패널의 과열을 방지하도록 하고 있다.
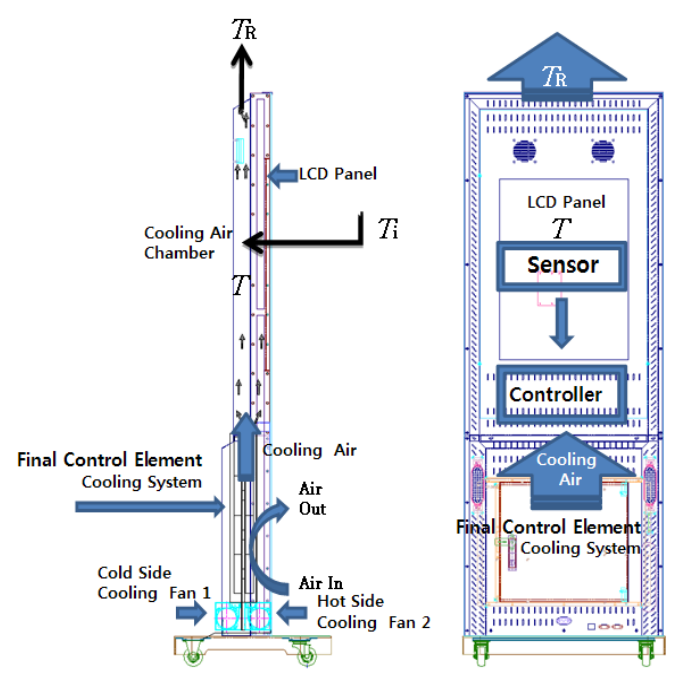

[그림 2] 콘솔의 구성 요소 간 상호작용 개념도

다음은 본 연구에서 전개하는 수식과 논리전개에 필요 한 조건 및 가정과 주요한 문자기호에 대하여 정리해 두 고자 한다. 첫째, $\mathrm{LCD}$ 패널에서 발생하여 냉각실로 유입 하는 열을 $T_{i}$ 로 하고 유입량은 단위 시간당 질량 $w$ 로 일 정한 유동량을 갖는 것으로 한다. 둘째, 냉각실의 온도는 충분한 교반이 이루어져서 냉각실 안의 모든 유체의 온 도는 거의 동시에 동일한 온도 $T$ 가 된다는 것을 가정한 다. 셋째, 냉각장치의 제어 대상은 냉각실의 온도만으로 한다. 넷째, 냉각된 유체는 단위시간당 $w$ 의 유동량으로 일정하다. 다섯째, 앞의 모든 조건 하에서 냉각실에 머무 르고 있는 모든 유체는 동일하게 일정시간동안 유지됐다 가 방출되는데 방출되는 공기의 온도는 냉각실의 공기 온도와 같은 $T$ 인 것으로 가정한다. 여섯째, 냉각실로 유·출입되는 공기의 입력량과 출력량은 같은 것으로 한 다. 마지막으로 공기의 비열 $C$ 는 온도에 상관없이 일정 한 것으로 한다.

\section{2 에너지 균형을 이용한 제어전략}

그림 2에 있는 각 구성요소 간의 상호작용을 블록다이 어그램으로 나타내면 그림 3과 같다. 그림 3에서 보는 바 와 같이 콘솔의 냉각실은 교합점( $\otimes$ : Summing Junction) 으로 들어오는 두 개의 입력과 한 개의 출력을 가지고 있 다. 두 개의 입력 중 하나는 최종제어요소인 냉각장치에 서 들어오는 $q$ 인데 이것은 냉각실의 열을 식혀주는 역할 을 한다. 다른 하나는 $\mathrm{LCD}$ 패널에서 발생한 열인 $T_{i}$ 로 서 외란이다. 그리고 출력은 이들의 혼합으로 생성된 냉 각실의 온도 $T$ 가 된다. 


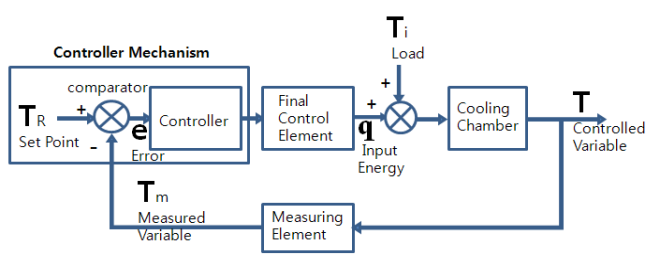

[그림 3] LCD 콘솔 냉각시스템 블록다이어그램

본 연구의 제어전략은 제어값 $T$ 를 기준입력 $T_{R}$ 과 같 게 해서 안정된 정상상태 즉 에너지 균형을 지속적으로 유지함으로써 LCD 패널이 과열되지 않도록 하는데 있기 때문에 냉각실의 에너지 균형의 차원에서 접근하는 것이다.

콘솔의 냉각장치 제어를 위한 핵심은 공정조건의 변화 로 인하여 외란 입력에 어떤 변화가 발생했을 때 제어기 로 하여금 이를 예측하고 대응할 수 있도록 하는 것이다. 이와 같은 목적에서 도입한 것이 전달함수이다. 먼저 희 망하는 정상상태 하에서의 냉각실에 대한 에너지 균형식 을 도입하면 식(1)과 같다.

$$
q_{s}=w C\left(T_{s}-T_{i s}\right)
$$

여기에서 $q_{s}$ 는 정상상태 하에서 냉각시스템으로부터 냉각실로 유입되는 열량, $T_{s}$ 는 정상상태에서의 냉각실 온도, $T_{i s}$ 는 외란으로서 정상상태 하에서의 $\mathrm{LCD}$ 패널로 부터 냉각실로 유입되는 온도를 나타낸다. 첨자 $s$ 는 정 상상태 설계 값을 나타내기 위하여 사용되었다.

만족한 제어가 이루어졌을 때 정상상태에서 방출되는 냉각실의 온도 $T_{s}$ 는 기준입력(희망온도)인 $T_{R}$ 과 같은 상태가 된다고 할 수 있으므로 식(1)을 $T_{R}$ 에 대하여 정 리하면 식(2)와 같이 다시 정리할 수 있다.

$$
q_{s}=w C\left(T_{R}-T_{i s}\right)
$$

그러나 냉각장치가 일정한 입력 열량 $q_{s}$ 만 전달하도 록 고정되어 있다면 공정조건이 바뀌고 $T_{i}$ 에 적은 변화 라도 발생했을 때 냉각실의 온도는 균형이 깨어진다. 때 문에 희망하는 정상상테를 유지할 수 있도록 추가적인 에너지 $q$ 를 공급할 수 있는 냉각장치와 제어기가 필요하 다. 그리고 제어기는 정상상태와 과도상태 모두에서 에너 지 균형에 대응할 수 있어야 한다. 과도상태에서의 에너 지 균형은 특정한 시점에서 시간의 변화에 따라 증감하 는 에너지의 변화량에 의하여 결정된다고 볼 수 있으므 로 식(3)을 도입하였다.

$$
E_{\text {acc. }}=\rho V C \frac{d T}{d t}
$$

여기에서 $E_{a c c}$ 는 축적에너지, $\rho$ 는 유체의 밀도, $\mathrm{V}$ 는 냉각실의 체적, $\mathrm{t}$ 는 독립변수로서 시간이다. 본 연구에서 는 입력과 출력 유량이 같다고 가정하였으므로 $\rho V$ 항은 일정하다고 볼 수 있기 때문에 앞의 식들을 종합하면 식 (4)를 유도할 수 있다.

$$
\rho V C \frac{d T}{d t}=w C\left(T_{i}-T\right)+q
$$

따라서 식(1)의 정상상태에 대한 해를 구하는 방법은 식(5)의 미분 값이 0 이 되도록 하는 것이므로 본 연구에 서는 이와 같은 전략에 따라 제어기를 설계하고자 한다.

\section{3. 제어 시스템 설계}

\section{1 시스템 모델링[5]}

그림 3 에서 교합점으로 들어오는 입력을 $q$ 와 $w C T_{i}$ 그리고 이들의 반응으로 결정되는 출력을 $w C T$ 가 되는 것을 앞에서 정리하였다. 입력과 출력은 모두 기준입력 $T_{R}$ 에 의하여 총 응답의 결과인 편차변수로 그 크기를 나타낼 수 있기 때문에 본 연구에서는 이 편차변수를 이 용하여 냉각실의 과도상태에 대한 에너지 균형을 예측할 수 있도록 식(5)을 도입하였다.

$$
\begin{aligned}
& q+w C\left(T_{i}-T_{R}\right)-w C\left(T-T_{R}\right) \\
& =\rho C V \frac{d T}{d t}
\end{aligned}
$$

정상상태 하에서 $d T / d t=0$ 가 되어야 하므로 식(5)는 정상상태에서 식(6)과 같이 됨을 알 수 있다.

$$
q_{s}+w C\left(T_{i s}-T_{R}\right)-w C\left(T_{s}-T_{R}\right)=0 \text { (6) }
$$

따라서 정상상태와 과도상태 간의 에너지 균형을 알아 보기 위하여 식(5)로부터 식(6)을 빼면 식(7)이 된다.

$$
\begin{aligned}
& q-q_{s}+w C\left[\left(T_{i}-T_{i s}\right)-\left(T-T_{s}\right)\right] \\
& =\rho C V \frac{d\left(T-T_{s}\right)}{d t}
\end{aligned}
$$

식(7)에서 주목할 것은 기준온도 $T_{R}$ 이 제거된 것을 볼 
수 있다. 이것이 의미하는 것은 콘솔의 내부온도가 일단 정상상태에 도달하면 기준입력에 관계없이 그 상태를 지 속적으로 유지기 위하여 추가로 필요로 하는 에너지의 양을 예측할 수 있다는 것이다.

여기에서 $T_{i}^{\prime}=T_{i}-T_{i s}, Q=q-q_{s}, T=T-T_{s}$ 와 같이 새로운 편차변수를 도입하면 식(7)을 식(8)과 같이 간략하게 정리할 수 있다.

$$
Q+w C\left(T_{i}^{\prime}-T^{\prime}\right)=\rho C V \frac{d T^{\prime}}{d t}
$$

식(8)에 대하여 라플라스변환을 실시하고 정리하면 식 (9)와 식(10)의 결과를 얻을 수 있다.

$$
\begin{aligned}
& Q(s)+w C\left[T_{i}^{\prime}(s)-T^{\prime}(s)\right]=\rho C V s T^{\prime}(s) \\
& T^{\prime}(s)\left(\frac{\rho V}{w} s+1\right)=\frac{Q(s)}{w C}+T_{i}^{\prime}(s)
\end{aligned}
$$

위의 식들을 이용하여 출력변수 $T^{\prime}(s)$ 와 두 입력변수 와의 관계로 정리하면 식(11)과 같다.

$$
\begin{aligned}
& T^{\prime}(s)=\frac{1 / w C}{\tau s+1} Q(s)+\frac{1}{\tau s+1} T_{i}^{\prime}(s) \\
& \text { 여기에서 } \tau=\frac{\rho V}{w} \text { 이다. }
\end{aligned}
$$

식(11)은 중요한 의미를 갖는다. 그 이유는 두 개의 입 력과 한 개의 출력 간의 관계에서 개별입력에 대한 출력 의 결과를 알 수 있도록 해주기 때문이다. 식(11)에서 입 력이 $Q(t)$ 에만 있고 $T_{i}^{\prime}(t)=0$ 일 때와 $T_{i}^{\prime}(t)$ 에만 있고 $Q(t)=0$ 일 때를 정리하면 식(12) 및 식(13)과 같은 결과 를 얻을 수 있다.

$$
\begin{aligned}
& \frac{T^{\prime}(s)}{Q(s)}=\frac{1 / w C}{\tau s+1} \\
& \frac{T^{\prime}(s)}{T_{i}^{\prime}(s)}=\frac{1}{\tau s+1}
\end{aligned}
$$

식(12)와 식(13)의 관계를 블록다이어그램을 이용하여 나타내면 그림 4 와 같다.

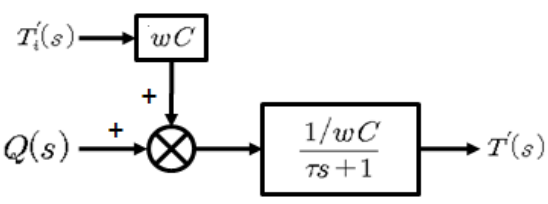

[그림 4] 냉각실 입출력 다이어그램

\section{2 파라미터 동정과 모델링 검증[3][6]}

지금까지 냉각실의 전달함수를 구하고 블록다이어그 램으로 나타내 보였다. 여기에서는 모델링이 정확히 이루 어졌는지 실험을 통하여 확인하고자 한다. 그 이유는 모 델링의 정확성을 확인할 수 있어야 이 후에 추진되는 연 구의 결과에 대해서도 신뢰할 수 있기 때문이다.

먼저 실제 시스템을 대상으로 냉각실의 열용량분석과 동특성 파라미터를 구하는 실험을 실시하였다. 실험에서 는 초기온도 $27.5^{\circ} \mathrm{C}$ 의 정상상태에서 $\mathrm{LCD}$ 패널을 작동하 고 냉각장치를 작동하지 않은 상태에서 1 분 단위로 30 분 동안 온도변화를 측정하여 그림 5 의 실제온도 커브와 같 은 결과를 얻었다. 그림 5 에서는 지면의 제약으로 2 분 단 위로 보여주고 있다.

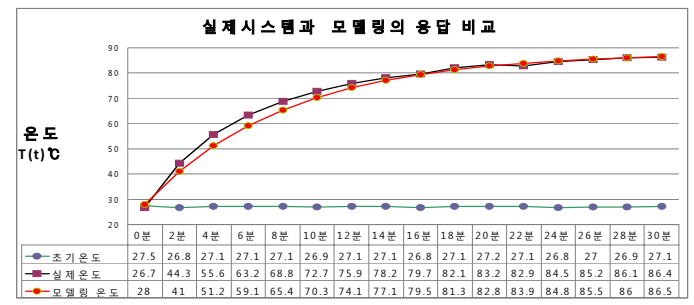

[그림 5] 냉각실의 응답비교

이어서 모델을 이용한 모의실험을 실시하였다. 모의실 험에서도 모든 입력조건은 실제시스템과 같다. 계단입력 의 크기를 $M$ 으로 하였을 때 입력 $T_{i}^{\prime}(t)$ 의 전달은 식 (14)과 같다.

$$
T_{i}^{\prime}(s)=\frac{M}{s}
$$

그리고 식(13)과 식(14)를 결합하면 식(15)를 얻을 수 있다.

$$
T^{\prime}(s)=\frac{M}{s} \frac{1}{\tau s+1}
$$

부분분수전개 후 역변환하고 시간영역 해석을 위하여 식(16)과 같이 정리하였다.

$$
T(t)=M\left(1-e^{-t / \tau}\right) \quad t \geq 0
$$

식(16)을 이용한 시뮬레이션에서 $M=60\left[{ }^{\circ} \mathrm{C}\right]$, 초기온 도 $27.5^{\circ} \mathrm{C}$, 시정수 $\tau=8.23$ (분)으로 하여 그림 5 에 있는 모의실험 커브와 같은 결과를 얻었다. 두 개의 결과에 대 하여 분산분석을 실시하고 유의수준 $5 \%$ 범위 내어서 차 
이가 없다는 결과를 얻었다. 따라서 성공적인 시스템 모 델링이 이루어 졌음을 확인하였다.

\section{3 제어기 설계}

본 연구에서는 편의상 제어기와 최종제어요소(냉각장 치)를 결합시켜서 그림 6과 같이 하나의 블록으로 나타내 었다. 그 이유는 앞에서도 언급한 바와 같이 냉각실의 상 태는 총 응답의 결과로서 최종제어요소의 반응이 포함되 어 있기 때문이다.

본 연구에서는 PI(proportional Integral) 제어모드를 채 택하였다. 그 이유는 제어기의 빠른 응답과 지속적으로 안정된 상태를 유지하기 위해서는 속응성과 정밀성이 중 요하다고 판단되었기 때문이다. 따라서 제어기에서 결정 하는 냉각에너지의 크기는 식(17)과 같이 나타낼 수 있다.

$$
q_{c}=K_{c} e+\frac{K_{c}}{\tau_{I}} \int_{0}^{t} e d t+A_{c}
$$

여기에서 $e=T_{R}-T_{m}$, 이다. 그리고 $T_{m}$ 은 측정온 도, $K_{c}$ 는 제어이득, $\tau_{I}=$ 적분시간(min.), $A_{c}$ 는 정상상태 즉, $e=0$ 일 때의 입력을 뜻한다. 그리고 $s$ 는 라플라스 연산자이다. 정상상태에서는 $T_{R s}=T_{s}=T_{m s}$ 가 되므 로 $e$ 에 대한 편차변수 $e^{\prime}$ 는 식(18)과 같다.

$$
e^{\prime}=e-e_{s}
$$

여기에서 $e_{s}=T_{R s}-T_{m s}, T_{R s}=T_{m s}$ 이기 때 문에 $e_{s}=0$ 이 되어서 식(18)은 식(19)과 같이 됨을 알 수 있다.

$$
e^{\prime}=e-0=e
$$

여기에서 $e$ 는 그 자체가 편차변수가 된다는 것을 의 미한다. 정상상태에서 편차 $e_{s}$ 는 0 이기 때문에 정상상태 의 열량 $q_{s}$ 는 식(20)과 같이 쓸 수 있다.

$$
q_{s}=K_{c} e_{s}+\frac{K_{c}}{\tau_{I}} \int_{0}^{t} e_{s} d t+A_{c}=0+A=A
$$

식(20)은 식(21)과 같이 정리할 수 있다.

$$
q=\left[K_{c}\left(1+\frac{1}{\tau_{I}} \int_{0}^{t} d t\right)\right] e+q_{s}
$$

or

$$
Q=\left[K_{c}\left(1+\frac{1}{\tau_{I}} \int_{0}^{t} d t\right)\right] e
$$

여기에서 $Q=q-q_{s}$ 이다. 따라서 제어기의 전달함수 를 식(22)와 같이 정리하고 블록다이어그램으로 나타내 면 그림 6과 같다.

$$
Q(s)=\left[K_{c}\left(1+1 / \tau_{I} s\right)\right] e(s)
$$

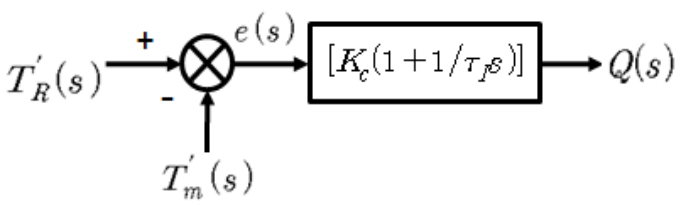

[그림 6] 제어기의 블록다이어그램

\section{4. 제어결과에 대한 고찰}

\section{1 전체 제어장치[7]}

지금까지 연구한 결과를 종합 정리하여 그림 7과 같은 전체 제어장치에 대한 블록다이어그램과 전달함수를 얻 었다.

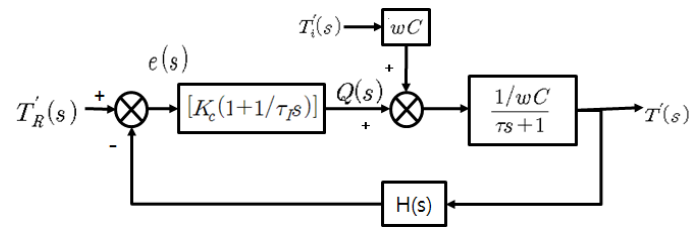

[그림 7] 전체시스템 블록다이어그램

본 장치에서 측정지연은 없는 것으로 하기 때문에 $H(s)$ 는 단위귀환이 된다. 그리고 식을 간략하게 하기 위해서 편의상 $w C^{-1}$ 를 $A$ 로 치환해서 그림 8 에 대한 전 체장치의 전달함수를 구하면 식(23)과 같다.

$$
\frac{T^{\prime}}{T_{R}^{\prime}}=\frac{K_{c} A\left(1+1 / \tau_{I} s\right)[1 /(\tau s+1)]}{1+K_{c} A\left(1+1 / \tau_{I} s\right)[1 /(\tau s+1)]}
$$

식(23)을 전형적인 2차계로 변환하기 위한 새로운 변 수 $\tau_{1}=\sqrt{\left(\tau \tau_{I}\right) /\left(K_{c} A\right)}$ 와

$\zeta=0.5 \sqrt{\tau_{I} / \tau}\left[\left(1+K_{c} A\right) / \sqrt{K_{c} A}\right]$ 를 도입하여 $T^{\prime}$ 에 대하여 정리하면 식(24)를 유도할 수 있다. 


$$
T^{\prime}=\frac{\tau_{I}}{\tau_{1}^{2} s^{2}+2 \zeta \tau_{1} s+1}+\frac{1}{s} \frac{1}{\tau_{1}^{2} s^{2}+2 \zeta \tau_{1} s+1}
$$

시간영역 해석을 위하여 식(24)를 역변환하면 식(25) 와 같다.

$$
\begin{aligned}
T^{\prime}= & \frac{\tau_{I}}{\tau_{1} \sqrt{1-\zeta^{2}}} e^{-\zeta t / \tau_{1}} \sin \sqrt{1-\zeta^{2}} \frac{t}{\tau_{1}} \\
& +1-\frac{1}{\sqrt{1-\zeta^{2}}} e^{-\zeta t / \tau_{1}} \\
& \sin \left(\sqrt{1-\zeta^{2}} \frac{t}{\tau_{1}}+\tan ^{-1} \frac{\sqrt{1-\zeta^{2}}}{\zeta}\right)
\end{aligned}
$$

\section{2 제어실험과 결과 비교[4]}

본 연구에서는 실제 장치를 대상으로 기준입력 (Set-Point)을 $32^{\circ} \mathrm{C}$ 로 설정하고 제어를 실시하여 그림 8과 같은 결과를 얻었다. 그림 8 은 동일한 조건에서 3 회 반복 실험을 실시하여 가장 좋은 결과를 보이는 경우를 제시 하였다.

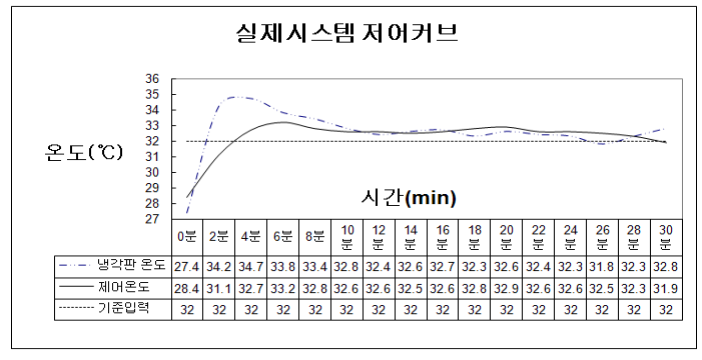

[그림 8] on-off 제어결과

이어서 실제 실험에서 구한 시스템 파라미터와 표 1 에 서 제시하는 제어기 파라미터를 이용하여 식(25)에 의한 모의실험을 실시하고 그림 9 와 같은 결과를 얻었다.

[표 1] 모의실험을 위한 파리미터 대조표

\begin{tabular}{|c|c|c|c|c|}
\hline 파라미터 & 1차실험 & 2차실험 & 3차실험 & 4차실험 \\
\hline$K_{c}$ & 1 & 1.5 & 2 & 1 \\
\hline$\tau$ & 8.23 & 8.23 & 8.23 & 8.23 \\
\hline$\tau_{I}$ & 0.2 & 0.5 & 1 & 1 \\
\hline$\tau_{1}$ & 0.507137 & & & \\
\hline$\zeta$ & 0.2 & 0.5 & 0.8 & 0.8 \\
\hline$\sqrt{1-\zeta^{2}}$ & 0.979796 & & & \\
\hline
\end{tabular}

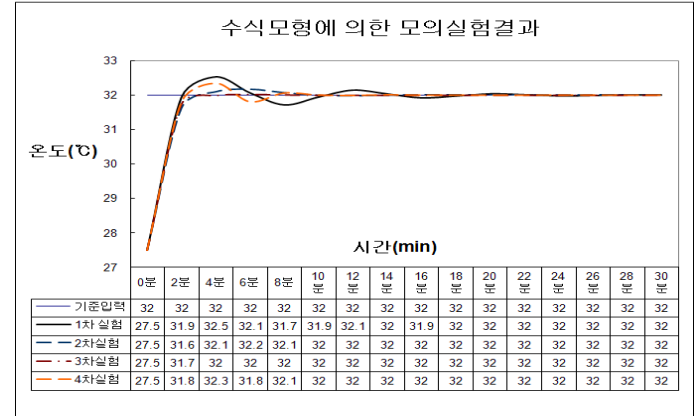

[그림 9] 수식모형을 이용한 시뮬레이션 결과

실제 실험의 결과와 모의실험에서의 결과를 비교하기 위하여 표 2 를 작성하였다.

[표 2] 성능 비교표

\begin{tabular}{|c|c|c|}
\hline 구분 & 차수 & 제어면적 \\
\hline 실제시스템의 제어기 성능 & 대표실험 & 516.1000 \\
\hline \multirow{3}{*}{ 모의 실험의 제어기 성능 } & 1차 & 507.8257 \\
\cline { 2 - 3 } & 2차 & 507.3890 \\
\cline { 2 - 3 } & 3차 & 507.2697 ※ \\
\cline { 2 - 3 } & 4차 & 507.5022 \\
\hline
\end{tabular}

표 2에서 제어면적이란 시간과 온도에 의하여 만들어 지는 개념적인 것을 의미하기 때문에 비교를 위하여 크 기만 알 수 있으면 되므로 단위개념은 필요하지 않다. 이 분석에서 값이 클수록 제어성능이 낮다는 것을 의미한다.

따라서 비교결과 이론과 실제의 차이를 고려하더라도 개선의 여지가 많은 것으로 판단되기 때문에 본 연구가 제안하는 제어전략을 실현할 수 있는 제어장치로의 개선 이 요구된다. 특히 제시되는 제어기 파라미터에 많은 의 미를 두고자 한다.

\section{5. 결론}

본 연구는 $\mathrm{LCD}$ 콘솔용 냉각장치의 제어성능 개선을 위하여 추진되었다. 연구의 대상이 되는 냉각장치는 $\mathrm{LCD}$ 콘솔에서 요구되는 하드웨어적인 장점뿐만 아니라 우수한 성능을 보장하기 위해서 제어시스템과 제어전략 도 함께 고려되어야 한다는 것은 주지의 사실이다. 이를 위하여 본 연구가 지금까지 추진한 결과를 정리하면 다 음과 같다.

첫째, 제어기로 하여금 정상상태와 과도상태의 모든 
시간영역에서 발생하는 에너지 균형을 예측하는 전달함 수를 제시하였다. 시스템 모델링 과정에서 최종제어요소 를 총 응답의 결과에 포함시키는 이유와 모델링 과정을 보였다. 둘째, 실제시스템을 대상으로 동특성분석 실험을 실시하고 실험에서 구한 파라미터를 이용하여 수식모델 에 의한 모의실험을 실시한 후 두 실험의 결과를 검정을 통하여 비교 분석하였다. 검정결과 유의수준 $5 \%$ 범위 내 어서 차이가 없다는 성공적인 결과를 얻어서 수식모델에 대한 신뢰성을 확보할 수 있었다. 셋째, 본 연구에서 콘솔 의 냉각시스템을 위한 제어 전략은 속응성과 정밀성이 보다 중요하게 인식되었기 때문에 PI제어모드를 설정하 고 제어기 설계과정을 보였다. 넷째, 실제 시스템의 제어 결과와 본 연구에서 제시하는 파라미터를 이용하여 시뮬 레이션을 실시한 후 두 결과에 대하여 제어면적 평가법 을 이용하여 비교 분석함으로써 개선된 방향을 제시하였다.

본 연구를 통하여 소기의 목표를 달성하였다. 다음의 연구는 본 연구에서 제시하는 제어 전략을 실현할 수 있 는 우수한 성능의 제어장치를 개발하는 것이다.

\section{참고문헌}

[1] 최갑용, "LCD 패널을 탑재한 옥외 광고용 콘솔 개발 에 관한 연구”, 한국산학기술학회 논문지, 제 11 권, 제 1호, pp. 13-20, 1월, 2010.

[2] 박종복, "디지털 전광판 LCD 판넬용 냉온시스템 개 발”, 중소기업청, 산학공동기술개발보고서, 7월, 2009.

[3] 장근선 외, “핀-튜브 열교환기와 알루미늄 열교환기 의 전열성능과 압력강화 특성비교", 산학기술학회 논 문지, 제10권, 제2호, pp. 222-229, 2월, 2009.

[4] R. Yun, "Evaluation of Performance of a Residental Air-Conditioning System Using Micro-Chanel and Fin-tube Heat Exchanger", Proceedings of the SAREK, pp. 28-35, 2007.

[5] Donald R. Coughanowr,"Process Systems Analysys and Control”, McGRAW-HILL, pp.249-281, 2002.

[6] 박성현, “현대실험계획법”, 대영출판사, pp.115-140, 3 월, 2002년

[7] Young Chul Kwon ;Jeong-tae Kwon ;Ji Hwan Jeong ;Sang Jae Lee ;Dae Hun Kim "Performance of a 2 room multi-heat pump with a constant speed compressor", Society of Air-Conditioning and Refrigerating Engineers of Korea. vol.12 no.4 pp. 184-191, 12. 2004.

\section{최 갑 용(Kab-Yong Choi)}

[정회원]

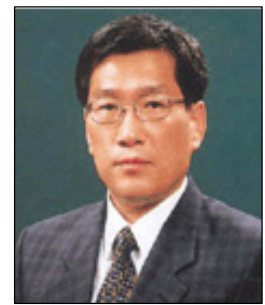

- 1996년 8월 : 숭실대학교 대학원 산업공학과 졸업(공학박사)

- 1997년 3월 현재 : 아주자동 차대학 자동차계열 교수(자동차 개발전공, 금형전공)

<관심분야>

시스템 설계/제어, $\mathrm{CAD} / \mathrm{CAM} / \mathrm{CAE}$

\section{오 태 일(Tae-Il Oh)}

[정회원]

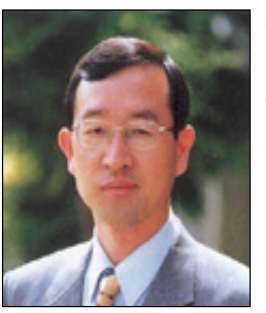

1990년 2월 : 서울대학교 대학원 기계과 졸업(공학석사)

- 2002년 3월 : 서울대학교 대학원 기계과 (공학박사 수료)

- 1998년 3월 현재 : 아주자동 차대학 자동차계열 교수(자동차 진단제어전공)

<관심분야>

자동차진동소음, 부품설계 